\title{
Eduardo Blanco Amor como teórico de la autotraducción
}

\author{
Xosé Manuel Dasilva \\ Universidad de Vigo \\ jdasilva@uvigo.es
}

Recibido: 8 de diciembre de 2012

Aceptado: 27 de febrero de 2013

\section{RESUMEN}

Eduardo Blanco Amor, uno de los principales escritores gallegos contemporáneos, tradujo varias obras suyas del gallego al castellano y también del castellano al gallego. En el género narrativo hay que mencionar A esmorga (La parranda), Os biosbardos (Las musarañas) y Xente ao lonxe (Aquella gente...). Dentro del género dramático, se trasladó a sí mismo en el caso del volumen Farsas (Farsas para títeres). A partir de tal actividad, Blanco Amor reflexionó de forma reiterada en torno a la práctica de la autotraducción. El presente trabajo tiene como objetivo abordar tales reflexiones, que ofrecen una visión particular sobre el hecho autotraductor.

Palabras clave: traducción literaria, autotraducción, Eduardo Blanco Amor, censura.

\section{Eduardo Blanco Amor as a theorist of self-translation}

\begin{abstract}
Eduardo Blanco Amor, one of the leading Galician contemporary writers, translated a number of his works from Galician into Spanish and also from Spanish into Galician. Within the narrative genre, A Esmorga (Span. La parranda), Os biosbardos (Span. Las musarañas), and Xente ao lonxe (Span. Aquella gente...) deserve being mentioned; with regard to drama, he translated himself in Farsas (Gal. Farsas para títeres). It is against this background that Blanco Amor reflected on his activity of self-translation, and the present work aims to analyse those reflections, which offer interesting insights into the phenomenon of self-translation.
\end{abstract}

Keywords: literary translation, self-translation, Eduardo Blanco Amor, censorship.

Eduardo Blanco Amor (1897-1979) es uno de los grandes nombres de las letras gallegas del siglo XX. Emigrante desde muy joven en Argentina y exiliado después 
en ese mismo país, su trayectoria creadora tiene inicio en el género poético con varios libros en gallego antes de la Guerra Civil, como Romances galegos (1928) y Poema en catro tempos (1931). Más tarde, durante el período de posguerra, da a la luz en castellano la novela La catedral y el niño (1948). Su carrera como narrador en lengua gallega se desarrolla propiamente en la etapa de madurez. Se inaugura con la novela $A$ esmorga (1959) y sigue con el libro de cuentos Os biosbardos (1962). Tras otro libro de relatos en castellano, Los miedos (1963), la última contribución de Blanco Amor al género novelístico es Xente ao lonxe (1972). Así describe el escritor la circunstancia de haber empezado a cultivar la narrativa en edad avanzada:

Pero también confieso que el narrar en gallego (porque poetizar ya poetizo desde el año 1928, año en que salieron mis Romances galegos) es mi descubrimiento tardío; en realidad, un autodescubrimiento, un fascinante vicio que anima mi vejez, y que le insufla una alegría, no juvenil sino joven, sin tener que pasar por el trámite de pactar con el diablo y cargar con fastidiosas y teologales Margaritas, perpetuamente arrepentidas... (Costa Clavell 1972).

En el ámbito de la traducción, no cabe afirmar que Blanco Amor sea responsable de una labor destacable en lo que respecta a las obras de otros autores. Se tiene noticia de que a finales de los años 50 concibe el proyecto de trasladar al gallego alguna obra de Valle-Inclán. Es lo que le dice, sin disimular la envergadura de su propósito, al intelectual gallego Francisco Fernández del Riego en una carta del 11 de diciembre de 1957: "Ando con ganas de meterle mano a una traducción de ValleInclán... Claro que la hazaña es osada, pero sin una cierta osadía no se hace nada que tenga que ver con el futuro".

No existe constancia de que tal proyecto llegase a buen puerto. Sin embargo, Blanco Amor emprende en aquellos años, sobre todo por razones crematísticas, versiones de algunos autores extranjeros al castellano para Emecé Editores, radicada en Buenos Aires. Es el caso del ensayo El alma de la mujer, de la italiana Gina Lombroso, y de la biografía Juana de Arco, del inglés Hilaire Belloc. Por necesidad económica, Blanco Amor también prepara en la década de los 70 la versión en gallego de casi una decena de entregas de la serie Astérix. A la misma lengua traduce, si bien en este caso por decisión voluntaria, la colección Tres relatos porteños, primer libro del escritor argentino Arturo Cancela.

A la vista del magro balance expuesto, es preciso resaltar que, en calidad de traductor, Blanco Amor sobresale más bien al trasladar sus propias obras del gallego al castellano o viceversa. Un breve repaso a su quehacer como autotraductor permite observar que dicha ocupación comienza realmente con la versión en castellano de A esmorga, que aparece con el título La parranda en 1960. Años antes, Blanco Amor vierte al gallego dos fragmentos de La catedral y el niño, "Primaveira" y "Nouturnio", difundidos en el periódico galleguista A Nosa Terra, a mediados de 1942, bajo el epígrafe "Prosas europeas". La siguiente obra autotraducida es Os biosbardos, que pasa a llamarse Las musarañas (1975). Al poco tiempo, lo mismo ocurre con Xente ao lonxe, en la nueva versión titulada Aquella gente... (1976). En dirección inversa, esto es, del castellano al gallego, Blanco 
Amor transfiere el conjunto de piezas teatrales Farsas, ofrecidas al público como Farsas para titeres (1973).

Si el fruto del trabajo de Blanco Amor en condición de autotraductor no debe calificarse de intrascendente, una nota más que hay que poner de relieve es su propensión a meditar sobre tal actividad. Sin ninguna duda, estamos ante el escritor gallego con mayor número de reflexiones en torno a este fenómeno tan específico, que no insólito (Santoyo 2006: 25), hasta el punto de que puede ser considerado en cierta manera un teórico de la autotraducción (Dasilva 2010b: 266-267). Los pensamientos que refleja sobre el asunto se encuentran esparcidos en numerosos epitextos, fundamentalmente documentos epistolares y entrevistas, y de forma principal en algunos peritextos, como los prólogos tan sustanciosos que figuran en las versiones Farsas para títeres, Las musarañas y Aquella gente...

Una buena parte de las autotraducciones de Blanco Amor, por no decir la totalidad, tiene como razón de fuerza mayor su dedicación profesional a la literatura. Declara, con sutil ironía, que no es más que un «escritor de profesión, en el sentido más angustiosamente subsistencial, y sin siquiera esa Seguridad Social en la que caerme vivo...» (Costa Clavell 1975). Por ese motivo se encarga de poner sus obras en castellano, dado que el horizonte comercial del libro gallego es más limitado, sin garantizarle por lo tanto unos ingresos aceptables.

En algunos casos, Blanco Amor alega para autotraducirse otras justificaciones. Se puede citar el libro Los miedos, que según su testimonio escribe originalmente en gallego y traduce después al castellano para presentarlo al premio Nadal (Allegue 1993: 275). Adopta tal decisión supuestamente debido a que su novela anterior, $A$ esmorga, recibe entre los lectores gallegos una acogida para él pobre. Con relación precisamente a $A$ esmorga, su primera obra autotraducida, Blanco Amor relata que la versión en castellano tiene aquí origen en la prohibición que el texto gallego sufre por parte de la censura franquista (Dasilva 2010a: 130).

Por lo menos esto es lo que se desprende de una carta que remite al artista Isaac Díaz Pardo el 31 de octubre de 1956, donde comunica que, ante la imposibilidad de editarla en gallego en territorio español, pondrá la novela en castellano para publicarla en Buenos Aires en esta lengua. Sea o no este el móvil de la autotraducción, resulta innegable que Blanco Amor escribe $A$ esmorga -la mejor novela, probablemente, jamás creada en lengua gallega- a mediados de 1955 en poco menos de cinco meses. Su deseo inicial es que aparezca en Galicia estampada por la editorial Galaxia, pero las autoridades se oponen frontalmente aduciendo que se usa en el libro un "lenguaje soez" (Dasilva 2009: 41-42). El censor encargado de juzgar la obra, en tono bastante rudo, suscribe esta opinión negativa: "Burda novela corta, en gallego, en la que se narran las aventuras y desventuras de tres borrachos".

Tras esta tentativa frustrada, la primera edición de $A$ esmorga sale, tras algunos años todavía de espera, en la capital argentina (Blanco Amor 1959), imprimiéndose allí la versión castellana un año más tarde (Blanco Amor 1960). Con relación a esta primera autotraducción, Blanco Amor no formula por extenso ninguna impresión, aunque sí disponemos de algunos testimonios dispersos. Así, revela en una carta a Fernández del Riego, del 8 de abril de 1960, que la misión entraña un auténtico reto: "Como el texto depende tanto del lenguaje, me dio más trabajo la versión que el ori- 
ginal". Sobre la complejidad de traducir A esmorga, esto mismo repite en una entrevista: "Cuando me puse a la traducción, tardé tres meses, lo que demuestra la radical dependencia del idioma original" (Ruiz de Ojeda 1994: 140).

Desde el punto de vista idiomático, no hay duda de que $A$ esmorga simboliza un titánico empeño por ensanchar los cauces expresivos de la lengua gallega, en buena medida por contraposición al estilo de otros narradores coetáneos. Basilio Losada enjuicia en estos términos la apuesta de Blanco Amor:

La publicación de $A$ esmorga colocó a Blanco Amor en primera línea de la narrativa gallega de hoy. Prodigioso ejercicio de estilo, exploración a fondo de las posibilidades expresivas del gallego suburbano, desconcertante juego de humor y crueldad, de desgarro expresivo y de violencia escatológica, la novela de Blanco Amor era el contrapunto vivaz, vitalísimo y actual de las prosas refinadas e intemporales de Cunqueiro, o el complemento de los cuentos de Ánxel Fole, asentados en el ámbito rural gallego, con un juego de fantasía, humor y misterio que nos llevan a los límites del trasmundo (Losada 1975).

El desafío que afronta Blanco Amor en la autotraducción es trasplantar al castellano todos los logros verbales de $A$ esmorga, lo cual no constituye una tarea sencilla ni mucho menos. La prueba es que el escritor, a pesar de sus desvelos, queda descontento con el producto. Al valorar, años después, la versión en castellano de Farsas, apunta sobre la autotraducción de A esmorga en comparación con esta: "Su traducción [Farsas] al gallego me costó infinitamente más trabajo que el original, pero contrariamente a la de A esmorga, esta vez me complace" (Ruiz de Ojeda 1994: 155). Con motivo de la autotraducción de Os biosbardos, en una carta al escritor Xosé Neira Vilas, del 15 de febrero de 1976, Blanco Amor identifica el porqué de esa insatisfacción:

La versión de Os biosbardos ha causado sensación en los lectores en castellano. Ciertamente, por bien del gallego y del castellano, quise que la autotraducción fuese una tercera obra, con los inevitables préstamos de los dos idiomas, pero otra cosa. Para escarmiento tenía el de A esmorga, que por fidelidad a la lengua original salió en extremeño. Tal como decía el clásico: "Por ser para todos leal, se es para todos traidor", o algo por el estilo (Neira Vilas 2010: 58).

La parranda, como título, ya no resulta afortunado, puesto que no recoge la rica dimensión semántica de $A$ esmorga. Por lo demás, una prueba evidente del éxito reducido de la versión autotraducida es que los traductores a otras lenguas prescinden de utilizarla como texto de partida. Se comprueba en las versiones en bable ( $L a$ folixa, Mieres del Camín, Editora del Norte, 1996), italiano (A esmorga, Roma, Carocci editore, 2006; La baldoria, Firenze, Società Editrice Fiorentina, 2007), francés (La Noce, Dinan, Terre de Brume, 2007) e inglés (On a bender, Wales, Planet, 2012). Todas arrancan de la versión gallega, aunque para solventar algunos escollos acuden esporádicamente a la versión en castellano, más que nada para consultar la solución adoptada por el autor. 
Una característica que conviene poner de manifiesto es que esta primera autotraducción de Blanco Amor se erige en un magnífico ejemplo de "autotraducción transparente", de acuerdo con la categorización que nosotros postulamos, no de "autotraducción opaca" (Dasilva 2011). Es decir, no se oculta al receptor que se halla ante una traducción del autor que parte de un texto primigenio en otra lengua. Incluso en la versión cinematográfica de la obra, cuyo guión elabora Blanco Amor, dirigida por Gonzalo Suárez, en 1977, con el título Parranda, se hace constar que el argumento está basado en el libro $A$ esmorga. Efectivamente, en la autotraducción se señala de forma explícita en los títulos de crédito: "Título de la obra original, en idioma gallego: A esmorga. Traducción del autor" (Blanco Amor 1960). Más aún, se advierte en un peritexto:

En su versión original, La parranda fue calificada por la crítica como el aporte más considerable de los últimos tiempos a la prosa gallega, y como la novela más significativa de dicho idioma. José Rodrigues Lapa, destacado lingüista y crítico portugués, ha escrito acerca de este libro: "Es una novela extraña y poderosa, cuyos personajes se recortan, fuertes y palpables, en el escenario de la vieja Auria, hablando un idioma de excelente sabor popular. Nada le falta para que pueda considerársela como una pequeña obra maestra” (Blanco Amor 1960).

Si Blanco Amor no ahonda en la experiencia de verter él mismo $A$ esmorga, tal vez por ser entonces bisoño en esas lides, otra cosa muy distinta es lo que sucede con su siguiente autotraducción, Farsas para títeres, en esta oportunidad del castellano al gallego, que data de trece años más tarde (Blanco Amor 1973). Según la propuesta conceptual establecida por Grutman, se hace pertinente hablar en este caso de un claro modelo de "delayed auto-translation", esto es, de traducción de autor que surge algún tiempo después de haber salido el original (Grutman 1998: 19), pues existe una distancia temporal importante entre Farsas y Farsas para títeres.

Blanco Amor incorpora, en la versión en lengua gallega, un paratexto prologal, con la significativa designación "Xustificación para os lectores galegos", consagrado a detallar los avatares del texto en castellano y, de modo esencial, a comentar su práctica autotraductora. En cuanto a la primera cuestión, puntualiza que la primera edición en castellano de la obra, publicada en Buenos Aires (Blanco Amor 1953), incluye solo tres composiciones dramáticas: "Angélica en el umbral del cielo: farsa apacible", "La verdad vestida: farsa violenta" y "Amor y crímenes de Juan el pantera: farsa para títeres de cachiporra". La segunda edición, impresa en México, contiene ya las seis piezas que aparecen en la autotraducción (Blanco Amor 1962), que presenta por cierto un formato bilingüe.

Más interesante es, por descontado, lo que Blanco Amor expone en el citado prólogo acerca de su papel de autotraductor. Se reafirma en primer lugar en el sacrificio que comporta, por lo menos en su caso, transvasar una obra propia a otro idioma, demandando por ello la benevolencia de los lectores:

La novedad de la presente edición queda, ya lo he dicho, en su traducción a nuestra lengua. He aquí algo que se dice pronto. No obstante, yo -que encontraría razonable que el lector en castellano le pusiese a estas obritas todas las tachas que 
quiera, incluyendo la de su probable envejecimiento, pese a la intemporalidad de los temas, o de su tratamiento teatral-, le rogaría al lector gallego, que presta su fervor a estas nuevas labores a favor del aggiornamento de nuestra habla como lengua de cultura, le rogaría que me fuese tenido en cuenta el trabajo casi angustioso de su traducción (Blanco Amor 1973: 12).

No omite Blanco Amor aclarar por qué la autotraducción encierra una elevada dosis de esfuerzo. La razón estriba, tal como asegura, en que las piezas que conforman este libro nacen en su momento asociadas a un determinado vehículo de expresión que ahora irremediablemente debe cambiar:

Yo sabía bien lo que quería al escribirlas en castellano, pero no me hallaba capaz de aplicarles el mismo querer en nuestro idioma. Dentro de mis habituales manejos bilingües, el uso de la lengua nunca me ha sido una duda, una opción. Comienza siéndome una tensión, una decisión seguida luego valientemente hasta el final (Blanco Amor 1973: 13).

Y Blanco Amor añade, matizando su criterio antes de solicitar, otra vez, la comprensión del público:

Se comprenderá, pues, que el genio natural del idioma en el que fueron primeramente escritas [las piezas], quedaba en ellas tan sine qua non ceñido a unos ámbitos concretos, a unos contenidos psicológicos y a sus formas expresivas, tan inseparables de las raíces populares -Celestina, Pantera, Estoraque- y de su habla subsidiaria, tan polarmente diferentes de las nuestras, que si el lector, en general, no tiene por qué agradecerme el haberlas escrito, le ruego al lector gallego que me compadezca por el trabajo de haberlas traducido con la mínima pérdida posible en el trasiego (Blanco Amor 1973: 13).

Es factible apreciar que, a cada nueva autotraducción, sea esta una "supraautotraducción" o una "infraautotraducción” según la eficaz terminología por Grutman acuñada (Grutman 2011: 78-82), Blanco Amor siente paulatinamente un impulso más fuerte por cavilar sobre su doble cometido de autor y traductor. En la versión en castellano de la colección de cuentos Os biosbardos, puesta en circulación como Las musarañas dos años después de Farsas para títeres, antepone un prólogo de mediana extensión, con el elocuente título "Justificación", dedicado íntegramente a discurrir sobre la autotraducción, tanto de forma general como en referencia a su versión (Blanco Amor 1975).

Las musarañas es otra muestra de "autotraducción transparente", ya que en la página de créditos se informa: "Título original: Os Biosbardos". En la portada interior, además, se apostilla: "Traducción del autor". Por si aún quedasen dudas, en una de las solapas de la edición se enfatiza: "Las musarañas es la versión en castellano, realizada con minuciosa fidelidad en cuanto a forma y espíritu por el propio autor, de las auténticas piezas maestras de la literatura actual española que forman el volumen titulado originalmente Os biosbardos, publicado en 1963 por la editorial Galaxia” (Blanco Amor 1975). 
Blanco Amor es consciente de su interés en aumento por la autotraducción. Por eso abre el mencionado paratexto con estas palabras que buscan, desde el inicio, disculpar ese afán de explicarse: "El lector, especialmente el bilingüe, me permitirá algunas precisiones que no son, de modo alguno, exculpatorias sino descriptivas". En el prólogo de Las musarañas se centra primeramente en catalogar su adhesión a la narrativa en lengua gallega de "tardía" y "programática" (Blanco Amor 1975: 9). En verdad, su estreno novelístico en tal idioma se produce cuando tiene ya sesenta años, "después de media docena de libros en la lengua central" (Blanco Amor 1975: 9). En cuanto al segundo rasgo que se atribuye, Blanco Amor subraya que la entrada en la novelística gallega en fase provecta no hay que conceptuarla de espontánea ni banal. Tiene como finalidad deliberada, según él, concederle opciones más vastas en el campo de la narrativa al idioma de Galicia, vinculado tradicionalmente a la creación lírica, y además con un registro no desapegado de los usos populares a la vez que de plena actualidad:

Mi programática personal, ni propuesta ni con pretensiones de impuesta más allá del oficio sentido como misión, consistió, consiste, en aceptar la parte de riesgo que pudiera corresponderle en procura de una expresividad mayor para la vieja lengua, no sólo en su estilo, sino en la anchura, y decisión de su temática, sin dislocarla en el manejo y tramitación de lo meramente literario o, si se quiere, retórico, para que siguiese siendo esencialmente la misma que la gente entiende y habla y en cuyo uso se reconoce como elemento implícito de una cultura que le es connatural; claro está, todo ello sin revolcones en el estiércol folclórico ni en las facilidades de lo pintoresco. Tal preocupación de llegar a la gente, á xente, en su sentido más comunal, resultó ser el factor obsesionante que me llevó al uso literario de mi lengua natural, como un ejercicio sumamente perentorio y exigente, en el que desembocaba una larga experiencia, incluso didáctica, en el uso y manejo de la lengua central (Blanco Amor 1975: 10-11).

Conforme anota Blanco Amor, el perfil de cada uno de los idiomas con los que brega es lo que propicia que el receptor del texto autotraducido pueda detectar divergencias con el texto primigenio. A este respecto, invoca las connotaciones que el vocablo "traducir" posee en lengua inglesa: "La operación de traducir, que en inglés se dice, infielmente, trasladar, consiste (al menos a mi me consiste) en repensar, no sólo lexicológicamente, sino estilísticamente, lo que voy poniendo en la lengua receptora; además del qué el cómo" (Blanco Amor 1975: 12). En la combinación lingüística que integran el gallego y el castellano, hay que tener igualmente en cuenta, como Blanco Amor no se olvida de remarcar, el devenir histórico tan opuesto de ambos idiomas:

Y más en este caso en que había que pasar de una lengua acantonada en un finisterre que fue durante siglos una espiritual insularidad, frente a un mar que no iba a ninguna parte, y pronto cegado el camino, muy concreto y de poca irradiación, de las Peregrinaciones; de un lenguaje menestral, y aun menesteroso, y por tanto lleno de claves y supuestos del mero uso hablado, pasar, digo, al strip tease suntuoso de esta otra lengua largamente feriada y modelada en el toma y daca de las 
culturas, con siete largos siglos de hablares y escribires, como lengua de necesidad y como idioma de deleite artístico y de superfluidad creadora (Blanco Amor 1975: 12).

Blanco Amor hace hincapié en que la complejidad de dar nueva vida en otra lengua a un texto no conlleva en su caso transmutaciones estéticas, es decir, alteraciones en el dominio de la ficción. A esa posible tentación, tan acostumbrada en otros autotraductores que primordialmente hacen valer el rol de autores engendrando una "auto-traduction (re)créatrice" (Oustinoff 2001: 33-34), Blanco Amor alude de modo expreso. Lo hace echando mano de una inteligente metáfora, donde no está ausente la sugerencia del exceso que, a su entender, cometen los traductores autoriales que introducen modificaciones que van más allá de las competencias del traductor alógrafo: "No tengo lugar para más. Pienso, incluso, que pudo resumirse en la aclaración de que estas traducciones son versiones, que por pertenecer a un mismo autor, pues, gozan de cierta franquicia para modificar, claro que sin llegar al abusivo gato por liebre" (Blanco Amor 1975: 13).

Es extraordinaria la perspicacia con la que Blanco Amor incide en una de las peculiaridades más acusadas de la autotraducción, en la cual, en palabras de Hokenson y Munson, "the translator is the author, the translation is an original, the foreign is the domestic, and vice versa" (Hokenson; Munson 2007: 161). Santoyo delinea certeramente la libertad que atesora el autotraductor: "In fact, self-translators may handle their second texts in ways never allowed to any other translator, because they, and only they, may finally develop a new text with all the characteristics of a second original" (Santoyo 2004: 229). Filippakopoulou, en dirección semejante, pone el acento en la magnitud autorial de la autotraducción (Filippakopoulou 2005), lo mismo que hace Perry:

But in order to determine whether these shifts actually indicate differences between the two literary systems, one has to examine them not only in the light of original literary works, in the literature of the source text and in the literature of the target text, but also in the light of the continuation of the writer's work in the source language and in the light of his former work in the target language (Perry 1981: 181).

Curiosamente, Francisco Umbral repara en la versión autotraducida Las musarañas cuando sale a la calle. Escribe una reseña, bastante encomiástica, en la que glosa la brillante capacidad que exhibe Blanco Amor a la hora de transferir sus obras de una lengua a otra. Merece la pena transcribir, pese a su extensión, las palabras de Umbral:

Eduardo Blanco Amor pasó del gallego al castellano, y viceversa, con gran sutileza y ubicuidad, porque lo suyo es deslizarse, cuando escribe, cuando habla, y si se ha elogiado mucho lo impecablemente que se traduce a sí mismo, lo bien que se mueve entre las dos aguas de las dos lenguas, no creo yo que esto sea solo su especial mérito, sino que ni siquiera es mérito, pues esa acuidad es él, ese deslizamiento y esa posibilidad de pasar biosbardos de matute, como Juan Ramón pasaba mariposas blancas en un saco. 
Esto que Blanco Amor ha hecho tan bien, poniéndose a sí mismo en limpio -cuando tan limpio estaba ya en gallego- no es, como digo, un especial mérito, sino la mecánica misma de su creación, de su recreación, ya que todo el bloque de infancia galaica que nos dan los cuentos de este libro, queda bajo otra luz más dura cuando lo ilumina el idioma castellano, y es como si el escritor hubiera puesto su niñez, su intimidad, sus recuerdos, su paisaje primero, con un prisma más riguroso, no con peligro de destruirlo, sino, muy al contrario, con la astucia de salvarlo (Umbral 1976).

La última autotraducción acometida por Blanco Amor es la versión de la novela Xente ao lonxe, publicada como Aquella gente... (Blanco Amor 1976) al poco tiempo de haber aparecido Las musarañas. El escritor adiciona otro prólogo no poco esclarecedor, titulado "Justificación", aún de más páginas que el antecedente, en el que se preocupa nuevamente de abordar su faceta de autotraductor.

Al igual que las anteriores, Aquella gente... es una "autotraducción transparente". En los títulos de crédito se consigna: "Título original: Xente ao lonxe (Editorial Galaxia, Vigo, 1972). Autotraducción del autor" (Blanco Amor 1976). Y en la contracubierta de la edición se hace saber: "Aquella gente... -versión castellana, hecha por el propio autor, de Xente ao lonxe- es una de las mejores novelas de Eduardo Blanco Amor y posiblemente la más ambiciosa y lograda literariamente" (Blanco Amor 1976).

El proceso de gestación de la autotraducción de Xente ao lonxe es bastante azaroso. Gracias a varios epitextos, se verifica que Blanco Amor recibe una propuesta de la editorial Planeta para sacar la novela en castellano, pero el encargo no cuaja por causas ajenas a su voluntad. En una carta a Fernández del Riego, sin fecha aunque seguramente de 1975, el escritor hace esta confidencia que pone al descubierto la laboriosidad que implica el ejercicio de la autotraducción:

Después de tres versiones (novecientas carillas a manejar) discutidas con Baltasar Porcel, que dirige la colección más escogida de Planeta, al final Xente ao lonxe ha quedado convertida en Aquella gente, lejos ... La obstinación de Porcel, que conoce bastante el gallego, era conseguir "que la versión al castellano conservase, en el carácter de idioma recipiente, la plasticidad y la gracia estilística que hace tan insólita esta novela gallega aun en el panorama más amplio de la narrativa española". En esta muralla china o velo de Penélope he trabajado y destrabajado más de dos meses sin parar.

Editada en última instancia por Seix Barral, Blanco Amor obtiene en Aquella gente... un resultado que, según su confesión, le place en grado sumo. En una entrevista testimonia que, con esta novela, consigue descubrir precisamente el mejor mecanismo para transportar sus obras de un idioma a otro. Sin llegar a abusar de la condición de propietario del texto, Blanco Amor especifica que la siguiente facultad no está al alcance de un traductor alógrafo:

Eduardo, tú eres traductor de tus propios libros: ¿ha sido un suplicio? Pues me imagino que traducir tu propia obra es una agonía. 
(...) Yo traté de buscar la fórmula, la encontré a la altura de Xente ao lonxe, y es: leo la frase entera, la pieza gramatical entera, no la oración, y pienso cómo la hubiera escrito yo en castellano; y eso no lo puede hacer el traductor, porque está metiéndose en terrenos que no son de él, pero el autotraductor, sí. Claro que da mucho trabajo, por eso repito que me asombró el éxito de la traducción de Xente ao lonxe. Es un éxito de estilo (Ruiz de Ojeda 1994: 119-120).

El prólogo de Aquella gente... es diferente del que encabeza Xente ao lonxe, titulado "Prólogo útil". Blanco Amor se refiere en la introducción de la versión gallega al estímulo normalizador, en lo que atañe a la prosa en gallego, que está detrás de la novela, en coincidencia con lo dicho en el texto preliminar de Las musarañas, atrás analizado. Es perceptible que en el prólogo de Aquella gente... sintetiza esa misma idea, pero con un enfoque levemente distinto en atención a los lectores de la obra en castellano. La parte más novedosa de este preámbulo es, no obstante, la que se adentra en su función de autotraductor.

Blanco Amor pone énfasis, una vez más, en el sufrimiento que para él supone traducir sus propios textos. Se pronuncia, por otro lado, en lo tocante al porcentaje de reescritura que está detrás de sus autotraducciones, que no niega en absoluto. Sin embargo, sostiene que no cae en el riesgo de incurrir en ninguna traición:

[...] el lector tiene ahora ante sí una novela, buena o mala, exenta de otras implicaciones que no sean su condición de pieza literaria de la especie narrativa. Es decir, que queda librada -no faltaría más- a lo que puede ser como tal, aunque, eso sí, construida dentro de la caracterología de la gente que la puebla y traída ahora a un idioma distinto de aquel en que fue pensada y escrita, con las deformaciones y licencias que ello implica. Esto pasa con todas las traducciones cuando no se trata de obras de contenido mostrenco, de estilo convencional o de nada entre dos páginas. Pero lo normal se convierte en pavoroso cuando, como ahora, el traductor es el autor. En el trance, no caeré en la bajeza de pedirle al lector que me perdone las invenciones, que esas son siempre imperdonables; pero sí que me compadezca por el suplicio que supone la autotraducción sin que uno pueda consentirse, en lo posible, la autotraición (Blanco Amor 1976: 14-15).

Con relación a la intervención autorial de Blanco Amor en la producción del texto trasladado, Pérez García opina, tras haber examinado en detalle Aquella gente..., que se trata de una recreación más que de una mera traducción, siendo mucho más comunes las amplificaciones que las supresiones. De hecho, Pérez García concluye que la novela en castellano, debido a su distinta configuración, "puede considerarse también perteneciente a la literatura española" (Pérez García 1995: 148). Y ello a pesar de que Blanco Amor insiste en preservar la filiación gallega de la versión autotraducida, sin esconder que previamente existe, por consiguiente, un texto forjado en otra lengua (Martínez Olmo y Pérez García 1999: 360). Como asevera él mismo justamente en lo concerniente a la autotraducción de Xente ao lonxe, su estrategia se cifra "en repensar el texto de acuerdo con la lengua receptora e insuflarle, en lo posible, el genio de la lengua original" (Neira Vilas 2010: 58). 
En algún momento, de la autotraducción llega a decir Blanco Amor que es, con todas sus consecuencias, como trabajar "en carne propia" (Ruiz de Ojeda 1994: 120). De ahí procede acaso su notable sensibilidad para tomar en consideración repetidamente esta modalidad traductora, alrededor de la cual es capaz de emitir una serie de juicios que representan un atractivo aporte para singularizar una manifestación cada vez más habitual en los intercambios culturales. Tales juicios no llegan a componer un corpus doctrinario, pero también están lejos de aparentar una masa heterogénea de divagaciones. Más bien nos encontramos ante una mirada singular sobre la autotraducción, enunciada con perseverancia desde la práctica de la misma, que destila un importante grado de coherencia.

Otra conclusión que resulta imprescindible realzar es la lucidez de Blanco Amor para no eludir aspectos de la autotraducción hoy en día de vigente interés. Hagamos mención, entre ellos, a las relaciones culturales privativas que corresponde discernir entre lenguas asimétricas, como es el caso del gallego y del castellano. No se puede pasar por alto, asimismo, la vertiente estética que guarda la traducción de su propio texto por parte del autor, aprovechando este con frecuencia dicha operación para intercalar cambios de suma entidad.

Finalmente, hay que llamar la atención de manera insoslayable sobre la franca desenvoltura con la que Blanco Amor se consagra a analizar el acto autotraductor, sin despreciar ninguna ocasión de hacerlo. Se trata esta de una actitud verdaderamente encomiable, sobre todo cuando en la actualidad los autotraductores tienden cada vez más a cubrir su condición de tales con un tupido velo.

\section{Referencias bibliográficas}

Allegue, G., Eduardo Blanco Amor, diante dun xuíz ausente. Vigo: Editorial Nigra 1993.

Blanco Amor, E., Farsas. Buenos Aires: Ediciones López Negrí 1953.

Blanco Amor, E., Farsas para títeres. México: Ecuador 00' 0” 1962.

Blanco Amor, E., A esmorga. Buenos Aires: Citania 1959.

Blanco Amor, E., La parranda. Buenos Aires: Compañía Fabril Editora 1960.

Blanco Amor, E., Farsas para títeres. Sada: Ediciós do Castro 1973.

Blanco Amor, E., Las musarañas. Barcelona: Euros 1975.

Blanco Amor, E., Aquella gente... Barcelona: Seix Barral 1976.

Costa Clavell, X., «Un escritor emigrante, en busca de su identidad gallega», Tele/Expres (4-1975).

Dasilva, X. M., «As vicisitudes editoriais d'A esmorga», Grial 184 (2009), 36-51.

Dasilva, X. M., «A esmorga á luz da Penzol», en: CABrera, Ma D. / Monteagudo, H. (eds.), Fermín Penzol. Unha obra para un país. Vigo: Fundación Penzol - Galaxia 2010a, 130-131.

DASILVA, X. M., «La autotraducción vista por los escritores gallegos», en: GALLÉN, E. I

Lafarga, F. / Pegenaute, L. (eds.), Traducción y autotraducción en las literaturas ibéricas. Berna: Peter Lang 2010b, 265-279.

DASILVA, X. M., «La autotraducción transparente y la autotraducción opaca», en: DASILVA, X. M. / TANQueIro, H., (eds.), Aproximaciones a la autotraducción. Vigo: Academia del Hispanismo 2011, 45-67.

FilipPAKOPOUlou, M., «Self-Translation. Reviving the Author?», Other Words. The Journal for Literary Translators 25, 3 (2005), 23-27. 
Grutman, R., «Auto-translation», en: BAKER, M. (ed.), Roudletge Encyclopedia of Translation Studies. Londres / Nueva York: Routledge 1998, 17-20.

GrUtMAn, R., «Diglosia y traducción "vertical” (en y fuera de España)», en: DASILVA, X. M. / TANQueIro, H., (eds.), Aproximaciones a la autotraducción. Vigo: Academia del Hispanismo 2011, 69-91.

Hokenson, J. W. / Munson, M., The Bilingual Text. History and Theory of Literary SelfTranslation. Manchester: St. Jerome 2007.

LosADA, B., «Novelista gallego», Tele/Expres (4-1975).

Martínez Olmo, P. / PÉrez García, N., «Transferencias léxicas y riqueza verbal en la narrativa en castellano de Eduardo Blanco-Amor», en: Tes philies tade dora. Miscelánea léxica en memoria de Conchita Serrano. Madrid: CSIC 1999, 353-360.

NeIra VILAS, X., Cartas de vellos amigos 1959-1998. Vigo: Galaxia 2010.

Oustinoff, M., Bilinguisme d'écriture et auto-traduction (Julien Green, Samuel Beckett, Vladimir Nabokov). Paris: L'Harmattan 2001.

PÉrez García, N., «Eduardo Blanco-Amor, autotraductor: Aquella gente..., versión castellana de Xente ao lonxe», Livius 7 (1995), 133-148.

PERrY, M., «Thematic and Structural Shifts in Autotranslations by Bilingual Hebrew-Yiddish Writers», Poetics Today 2, 4 (1981), 181-192.

RuIZ DE OJeDA, V. A., Entrevistas con E. Blanco-Amor. Vigo: Nigra 1994.

SANTOYO, J.C., «Self-Translation: Translational Competence Revisited (and Perfomance as Well)», en: Fleischmann, E. / Schmitt, P. A. / WotjaK, G. (eds.), Translationskompetenz. Tübingen: Stauffenburg 2004, 223-235.

Santoyo, J. C., «Blank Spaces in the History of Translation», en: Bastin, G. L / Bandia, P. F. (eds.), Charting the Future of Translation History. Ottawa: University of Ottawa Press 2006, 11-43.

UMBRAL, F., «Del gallego al castellano. Las musarañas, la gran novela de Blanco Amor», La Vanguardia Española (8-1-1976). 